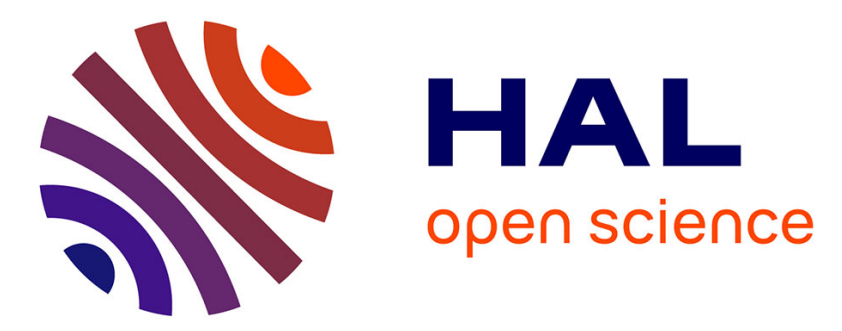

\title{
OPTIDENS: An optimization model to explore the conditions of possibility of slow but accessible urban areas
}

Cyrille Genre-Grandpierre, Alena Melnikava, Serigne Gueye, Philippe Michelon

\section{To cite this version:}

Cyrille Genre-Grandpierre, Alena Melnikava, Serigne Gueye, Philippe Michelon. OPTIDENS: An optimization model to explore the conditions of possibility of slow but accessible urban areas. Environment and Planning B: Urban Analytics and City Science, 2020, 48, pp.239980832091303. 10.1177/2399808320913034. hal-02543806

\section{HAL Id: hal-02543806 https://hal.science/hal-02543806}

Submitted on 18 Jan 2022

HAL is a multi-disciplinary open access archive for the deposit and dissemination of scientific research documents, whether they are published or not. The documents may come from teaching and research institutions in France or abroad, or from public or private research centers.
L'archive ouverte pluridisciplinaire HAL, est destinée au dépôt et à la diffusion de documents scientifiques de niveau recherche, publiés ou non, émanant des établissements d'enseignement et de recherche français ou étrangers, des laboratoires publics ou privés. 


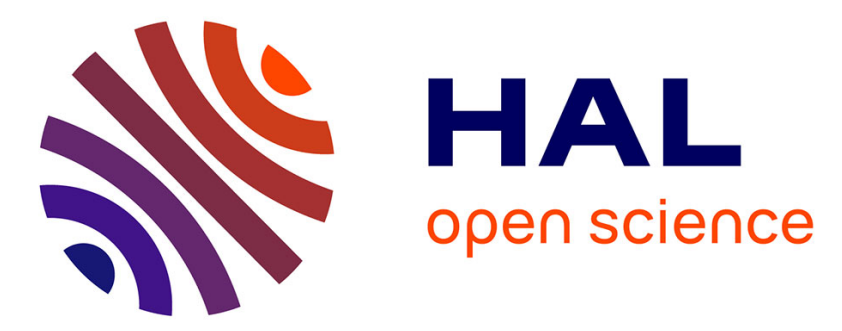

\section{OPTIDENS: An optimization model to explore the conditions of possibility of slow but accessible urban areas}

Cyrille Genre-Grandpierre, Alena Melnikava, Serigne Gueye, Philippe Michelon

\section{To cite this version:}

Cyrille Genre-Grandpierre, Alena Melnikava, Serigne Gueye, Philippe Michelon. OPTIDENS: An optimization model to explore the conditions of possibility of slow but accessible urban areas. Environment and Planning B: Urban Analytics and City Science, SAGE Publications, 2020, pp.239980832091303. 10.1177/2399808320913034. hal-02543806

\section{HAL Id: hal-02543806 \\ https: / hal.archives-ouvertes.fr/hal-02543806}

Submitted on 18 Jan 2022

HAL is a multi-disciplinary open access archive for the deposit and dissemination of scientific research documents, whether they are published or not. The documents may come from teaching and research institutions in France or abroad, or from public or private research centers.
L'archive ouverte pluridisciplinaire HAL, est destinée au dépôt et à la diffusion de documents scientifiques de niveau recherche, publiés ou non, émanant des établissements d'enseignement et de recherche français ou étrangers, des laboratoires publics ou privés. 


\section{OPTIDENS: an optimization model to expl
the conditions of possibility of slow but accessible urban areas}

Cyrille Genre-Grandpierre Alena Melnikava Serigne Gueye Philippe Michelon 


\section{Abstract}

High levels of population density and job accessibility are the very essence of urban areas, as they allow the emergence of agglomeration economies. In the past, slow modes of transportation meant population and activity densities as the only way to reach high accessibility levels. Then, the high speed provided by cars has enabled people to choose their home and job locations in larger areas, while keeping their daily transport times and budgets constant. As a consequence, this change in the nature of accessibility now based on speed rather than on physical proximity, has led to urban sprawl and automobile dependency, and in turn to environmental and social issues. To tackle these issues a renewal of greater urban density is often promoted, but high density has its own challenges (e.g. heat islands, air pollution) and is not well accepted by the population. In this context, an optimized model called OPTIDENS has been developed in order to explore how we might obtain urban areas with slow speeds and limited density but good accessibility. OPTIDENS reallocates activities (population, jobs) in order to meet contradictory expectations regarding urban forms and accessibility while minimizing car speed, which is a strategic goal in order to overcome automobile dependency. The model was tested in a mixed urban-rural area in the south of France. The results demonstrate that slow accessibility is possible and point out the relative impacts of the different constraints on urban forms and on the required speed.

\section{Keywords}

OPTIDENS, Urban form, Accessibility, Social Interaction Potential, Density, Travel Speed, Mixed-Integer Linear Programming 


\section{Introduction}

Urban forms can be seen as spatial structures which aim to maximize accessibility, defined as the quantity of resources (people, jobs, services) accessible from a given location, in a given time, by a given mode of transport (Handy and Niemeier (1997)). Individual high level of accessibility to people, often called the Social Interaction Potential (SIP) (Farber et al. (2014)), is indeed a fundamental human need, as it promotes social life(Urry (2002)). At the community level, a high SIP between numerous and diverse individuals and a high level of accessibility to jobs, services etc., enables the emergence of agglomeration economies, by ensuring a wide job market as well as the transmission of new ideas, thus fostering innovation and consequently economic growth and competitiveness (Prudhomme and Lee (1999); Glaeser (2011)). Hence, accessibility lie at the heart of urban form development (Batty (2013)).

When the modes of transport were slow, grouped activities and high population densities were the only way to attain high accessibility as they reduced the distances to travel. Then, the higher speeds permitted by car ownership and huge road investments gave more freedom to people and firms to optimize their location within larger areas in order to avoid density and its negative external factors (noise, lower access to natural activities, land prices, etc.). Hence, gains in travel speed have been systematically reinvested in the distance travelled to increase the level of choice (for housing, works, services) rather than used to lower the daily transport time budget, which remains constant at around $1.5 \mathrm{~h}$. (Zahavi and Talvitie (1980); Levinson and Kumar (1994)). This has led to urban sprawl, with high levels of accessibility no longer limited to the city center but widely dependant on the structure of the anisotropic road network, and to an urban functioning based on car speed rather than on physical proximity. The problem of such a functioning is that it makes people strongly reliant on the automobile (Newman and Kenworthy (1989); Dupuy (1999)). 
Without car speed, people are no longer able to perform their daily tasks, particularly in peripheral areas, as they rarely have an alternative mode of transport providing the same level of speed as a car to reach distant activities. Moreover, the scattered spatial structure based on car speed raises social issues. It may lower the potential for social activity (Farber and $\mathrm{Li}$ (2013)) and leads to issues in terms of inequality, because those without a vehicle do not have access to many activities located depending on car accessibility. It also leads to environmental issues as the distances travelled (in kilometers) increase, resulting in higher energy consumption, noise and pollutant emissions.

Thus, as this car use based functioning appears to be unsustainable, the question of possible alternatives is a central topic for urban planners. A first solution aims at providing true alternatives to the car in terms of accessibility in a cost-effective way. Unfortunately, this appears to be very difficult, especially in low density peripheries. Improved public transport, and cycling and walking facilities for shorter trips, appear to be necessary conditions but not sufficient in themselves. A shift is therefore needed from planning for mobility to planning for accessibility. In this perspective, planners often promote a revival of density as the main solution (e.g. the urban village group, Aldous (1997)). However a high density and compactness for a built-up environment present their own challenges. Firstly, density, and its desadvantages (especially for housing), is not well accepted by people. So it is politically very difficult to promote and reach an increase in density. Further, the controversy as to the sustainability of dense urban forms remains intense (Breheny (1992); Burton (2000); Neuman (2005)). Clearly, while density seems to be a lever to limit the distances travelled, it also leads to environmental issues (e.g. urban heat islands, pollutant concentration, artificialization of soil, low access to green spaces, etc.). Hence, as urban forms result from the interactions between transport and location systems in a coproduction 
process (Wegener and Fürst (1999); Wiel (2002)), and as urban forms have to meet various and sometimes contradictory requirements from planners, who aim at sustainability, and from individuals, who focus on individual utility, the solution for reaching sustainable accessibility and urban forms cannot be simple and cannot consist in a sterile opposition of density versus sprawl. As urban areas are complex systems (Batty (2007)), there is therefore a need for approaches at a higher level taking into account the entire mix of relations around the current car system (Urry (2008)). Practical tools are also necessary for sustainable planning to deal with this complexity, and more precisely with land use allocation and its interactions with transport.

Very inspiring works on fractal figures (Yamu and Frankhauser (2015)) and their ability to be optimal models regarding accessibility to different types of amenities in urban areas are an example of an innovative approach. Fractals appear to be a kind of trade-off allowing the opposition between dense and scattered forms to be overcome. Another more tool oriented approach consists in simulating urban functioning with Land Use Transport Interaction Models (LUTI) (Aretnze et al. (2000); Waddell (2001)) in a decision support perspective. These powerful models which use agent based modeling aim at simulating the behavior of different types of agents, households, firms, etc., in particular in terms of location choices, and their impact on urban form behavior. Another widely-used approach concerns the land use allocation problem, which can be defined as the process of allocating different activities (such as agriculture, housing, manufacturing industries, leisure activities) to specific units of area within a region (Porta et al. (2013)). In this category we find cellular automata (White et al. (2015)). Using rules regarding land use (maximum of population density for example), compatibility of adjacent types of land use, and transition rules, cellular automata simulate the allocation of the different activities, especially in a growth 
perspective. Optimization models are also found, as numerous studies have recognized the multi-objective nature of land use planning (Janssen et al. (2008)). In these models, the user defines the space required by the different types of activities, as well as the constraints (regarding for example the compatibility of adjacent types of land use), and gives an objective function, for example to maximize the net system benefit and/or minimize the environmental impact (Tan et al. (2017)). Then the model allocates activities in order to respect the constraints and to maximize the objective function. Depending on the complexity of the model (number of constraints, and types of land-use etc.), different resolution solutions exist such as linear programming methods (Aerts et al. (2003)), multi-objective integer or linear programming models (Nikkami et al. (2009)), and also genetic algorithms (Porta et al. (2013)).

All these tools have become more and more powerful as decision support tools in the short term, but they remain somewhat deficient when dealing with the question of an optimal combination of urban form transportation system to provide sustainable forms of accessibility. Simulation tools (such as LUTI) are mainly designed to evaluate different scenarios depending on the current urban functioning, rather than to provide information on the optimality of the scenarios and on what the combination urban form transportation system should be in a sustainable perspective. For example, the question of the optimal speed linked to the urban fabric is very rarely tackled or only theoretically taken into account (Banister (2011)). Moreover, it appears problematic to base planning in the medium to long-term strictly on the current functioning, in particular in terms of transportation and travel behavior, as this functioning may (and probably will) change dramatically in the future due to digital technologies (Urry (2002)), or to major social changes (for example, the ageing of the population or the unemployment growth). Thus in todays simulation or optimization models the city is considered in its 
current functioning (or a projected functioning, as in the fractal approach where people are supposed to systematically visit the closest amenities to their home, which is currently not the case), rather than as a resilient potential of accessibility, which appears in the long term to be its very essence. In the same vein the current models, particularly the optimization models, need to make many debatable assumptions regarding the growth of different economic sectors, their profitability or their impacts on the environment, which raises questions as to their robustness, even if some recent works have tried to integrate the question of uncertainty using probability (Tan et al. (2017)). Lastly, the current approaches to urban planning have mainly been designed in a perspective of urban growth rather than in a regeneration perspective for urban areas, while a lot of cities, especially in developed countries, are in fact stagnating or shrinking. For urban planners it is now important to know both how to manage the growth, but also how to transform the current urban forms to shift towards sustainability. Lets note that it has been estimated that every 20 years between 1/6 and 1/5 of a given urban zone undergoes functional changes, giving planners a real opportunity to transform the city (Piron (2003)). It is therefore still necessary to explore the possible conditions in urban areas of a sustainable accessibility, while taking into account the interdependence between transportation speed and urban forms to override the caricatural opposition between dense and sprawled cities. In this perspective, this paper describes the OPTIDENS model, which couples a geographical information system and an optimization model of mixedinteger programming. OPTIDENS optimally allocates or reallocates populations and activities, in order to meet numerous and potentially contradictory user expectations (such as low levels of local density and compactness, to meet peoples desires, versus high levels of accessibility and low space consumption, to meet the planners requirements), while minimizing travel speed by car. As previously mentioned, in a sustainable 
perspective decoupling accessibility from car speed appears to be a strategic goal. The higher the car speed, the less competitive public transport becomes, and the higher the possibility for people and firms to organize their daily functioning in large areas. This in turn leads to automobile dependency and environmental issues (Wiel (2002); GenreGrandpierre (2007)). The challenge therefore consists in finding suitable activity locations coupled with low car speeds to overcome the problem of automobile dependency, while meeting user expectations, especially in terms of accessibility level. Thus, OPTIDENS does not provide an optimal solution for land use. It is an exploratory tool which enables an estimation of the relative impacts on urban forms and on the required car speed of different user expectations. In broad terms, input which city you want and OPTIDENS will tell you if it is possible and under what conditions. The paper begins with a presentation of the optimization model. Next, results are given for an area in France studied to illustrate the exploratory capacities of OPTIDENS. Finally, some overall conclusions and the future milestones are given.

\section{OPTIDENS model}

OPTIDENS enables the possibility of conditions for sustainable accessibility to be explored, to drive sustainable changes in urban territories at the time when they are to be extended and mutated. Using OPTIDENS requires a description of the study area, and the setting of simulation parameters and the user expectations. OPTIDENS then finds the values of the decision variables to be located in each place, e.g. the number of people and/or jobs or services, in such a way that all expectations can be satisfied while minimizing the car speed (the objective function). In this work, people, jobs, services, etc. are named activities, which is considered as a broad notion corresponding to any human activity. 
The input data

In OPTIDENS, the study area is divided into square cells. The smaller the cell, the more precise the location of activities will be, but this increases the work to collect data, the model complexity and resolution time. Each cell, groups at least the current population, but also the number of jobs or public services etc. depending on the number of activities considered in the simulation. Whether or not the cell is constructible is set, as well as which types of activities can be located there. This can be done according to the current urban plans or, in a more exploratory way. By default, all the cells are suitable for all types of activities. As an option, a minimum and/or maximum level of activity for each cell can also be set if the user wants to ensure that the relocation process will not entirely empty some cells, or on the contrary concentrate all the resources in others. Choosing a high minimum also allows particular locations to be favored, for example cells close to public transport infrastructures for population location. This constitutes a way to limit automobile dependency (Curtis (2008)). Accessibility and local density are measured are the centers of the cells or a subset of these centers. Using a network analysis tool, the traveling costs are computed between all the cell centers in travel time (in minutes) and travel distance (in meters) by car, based on the current road network. Shortest paths in time take into account the different speeds allowed on the different types of roads and the one-way streets. The calculations are made under free flow conditions. Lets note that it is possible to use a distance matrix based only on public transport (here the question would be is it possible to reach a good accessibility without car ?) or a distance matrix which takes into account the shortest path by comparing the travel time by car and by other mean of transport. These cases are not explored in this paper. 


\section{The users expectations}

Users have to fix several thresholds corresponding to their expectations:

- the quantity of activity reachable in 15 minutes by car from the measurement points. These levels may be the same for all the measurement points, or different to preserve a part of the current urban structure. For the simulations described here in this paper, the travel time was set at 15 minutes because the idea was to achieve a territory which works at short range at the lowest possible speed. OPTIDENS uses a simple definition of accessibility because as shown by Bertolini et al. (2005), in order to usefully employ accessibility in interactive creative plan-making process, the measurement has to be sufficiently simple to manage.

- the maximum level for local population density, under the assumption that people do not accept a too high level of density. Local density is measured in a radius of 1000 meters around each measurement point and the area of the corresponding circle. A local measurement was used rather than a global measurement (average density in the study area, for example), as people are more sensitive to the density close to their home rather than in another part of the territory. The threshold of 1000 meters corresponds to a compromise between a very local view and an overly large view of the density when using higher thresholds, which will tend to smooth the spatial differentiations. Again, the user may set the same or different levels of local density for all the measurement points.

- the maximum threshold for cell compactness, corresponding to the rate of constructed area on the ground. This criterion is intended to satisfy the requirement for population spacing-out, but also to respect environmental issues (biodiversity, water infiltration, ventilation of the urban territories, etc.). 


\section{Parameters for the simulation}

Finally, users have to set some parameter values to control the simulation outputs:

- the ground surface required per unit of activity (surface per inhabitant, per job etc.). Greater surface areas required will result in less dense areas.

- the mutation ratio. OPTIDENS enables reallocation of all the current activities, or only a part (corresponding to the mutation ratio). Using a mutation ratio is much closer to planning reality, because in practice planners obviously cannot consider that it is possible to change everything at the same time. It is a lever for planners to estimate their room for maneuver: how many reallocations are needed to reach the goals in terms of accessibility and car speed? In the same approach to the question of urban dynamics, it is also possible to add new activities, for example to simulate a population growth. In this case OPTIDENS can optimally locate only the new or both the new and current activities.

Once the parameters have been set, OPTIDENS seeks to verify all the users expectations while minimizing the travel speed by car, in order to tackle the problem of automobile dependency. This link created between users expectations, urban form, and related speed is a major asset of OPTIDENS. The speed is a part of the solution, not an input of the model. Two options are possible to find the minimum speed:

- from a set of discrete speeds, OPTIDENS selects the lowest value which enables verification of all the expectations for all the measurement points. Thus, it is the worst (highest) speed. Locally, the required speed may be lower, but can never exceed the value obtained. 
- OPTIDENS searches for the minimum relative change value (decrease or increase) from the current speeds on different sections in the road network, so that all the expectations are verified. This change value is measured in \%, e.g. the resulting change value being $10 \%$ means that it is possible to reduce the current speed by $10 \%$ with the new locations of the resources, and to verify the constraints. With this option, not developed in this paper, the initial hierarchy in terms of speed between the sections is maintained.

Hence, it appears that OPTIDENS is neither a data consuming tool (it is possible to group only the population and the distance matrices), nor a tool requiring many assumptions. These are assets to ensure its widespread applicability. In the following section, a formal description of the model is presented.

\section{Mathematical model}

\section{Parameters}

In the sequel, a facility means a physical construction allowing to perform an activity type. If $a$ denotes an activity type (work, leisure, shopping,...), this activity is performed in one or several facilities of type $a$. The urban area into study is divided in square of equal surface called cells (Figure 1). Activities (or facilities) and cells parameters are then noticed as follows :

- $Z$ : set of cells, in which the zone is divided;

- $P$ : set of measurement points $(P \subset Z)$;

- $A$ : set of activities;

- $W$ : set of special areas for imposing maximum or minimum levels for each (or some) facility $a \in A$. One may for instance impose a minimum level of green area;

- $S_{z}$ : total surface of a cell $z \in Z$;

$-s_{a}:$ surface occupied by one unit of facility $a \in A$; 
$-\overline{\sigma_{a, p}}$ and $\underline{\sigma_{a, p}}$ : maximum and minimum levels of facilities $a \in A$ respectively, required to be accessible at specific time range from the measurement point $p \in P$;

- $\overline{\sigma_{a, W}}$ and $\sigma_{a, W}$ : maximum and minimum levels of the activities $a \in A$ for special areas;

- $Q_{a, z}:$ minimal (or not changeable) number of activity $a \in A$ in the cell $z \in Z$;

$-\overline{Q_{a, z}}$ : number of facilities $a \in A$ in the cell $z \in Z$ before reallocation;

$-\alpha_{a, z}$ and $\overline{\alpha_{a, z}}$ : lower and upper bounds on the number of facilities $\overline{a \in} A$ to be reallocated;

- tot $_{a}$ : total number of facilities $a \in A$;

$-V$ : set speed indices. $s p d_{v} \in V$ denotes the speed values corresponding to each index $v \in V$;

- $t$ : maximum time to reach activity $a \in A$;

- $r_{a}$ : land mutation ratio for each $a \in A$;

$-\delta_{p, z, v}$ : binary value defines as follows :

$$
\delta_{p, z, v}=\left\{\begin{array}{l}
1 \text { if speed } \operatorname{spd}_{v} \in V \text { allows to reach cell } z \in Z \text { from the } \\
\text { measurement point } p \in P, \text { within the time } t \\
0 \begin{array}{l}
\text { otherwise. }
\end{array}
\end{array}\right.
$$

These values are pre-calculated.

Our model also includes parameters defining whether a cell is reaffectable or not. That is whether it is possible, or not, to modify (by adding or erasing) the amount of facilities of different types it contains. These parameters are necessary due to the local urbanism documents, where the local authorities define whether a certain area is a built-up area or it needs to stay unconstructible (free space). To not introduce unecessary additional notations, we assume that all cells in $Z$ are reaffectable. 


\section{Decision variables}

The decision variables correspond to real-life decisions taken by decisionmakers on the facilities allocation. We notice :

$-y_{a, z} \geq 0$ : the number of facilities $a \in A$ to be allocated in the cell $z \in Z$. Although integrality would be necessary, we assume that $y_{a, z}$ is continuous (i.e. $y_{a, z} \in \mathbb{R}$ ). to avoid resolution difficulty due to the big number of these variables, and because rounding the fractional variables would just have a merely slight impact in practice.

$-x_{v}$ : a binary variable defined as follows:

$$
x_{v}= \begin{cases}1 & \text { if speed } v \in V \text { is selected } \\ 0 & \text { otherwise }\end{cases}
$$

$-\overline{y_{a, z}} \geq 0:$ a continuous variable equals to $\overline{y_{a, z}}=\mid \overline{Q_{a, z}}-\left(Q_{a, z}+\right.$ $\left.y_{a, z}\right) \mid, \quad \forall a, \forall z$. It contains the absolute deviation between the number of facilities $a \in A$ before and after reallocation. It is necessary to control the mutation ratio, which will be defined below.

\section{Objective function}

Our objective is to minimize the maximum travel speed :

$$
\min \sum_{v \in V} s p d_{v} x_{v}
$$

Thus, the objective value is an overall measure of accessibility and sustainability in the studied area. It gives the minimal authorized speed for meeting the constraints and can serve as a basis for speed policies. 


\section{Constraints}

- One single speed should be selected within the discrete set $V$ :

$$
\sum_{v \in V} x_{v}=1
$$

- For each measurement point $p \in P$ and each facility $a \in A$, we need to respect minimum and maximum accessibility level:

$$
\underline{\sigma_{a, p}} \leq \sum_{z \in Z} \sum_{v \in V} \delta_{p, z, v} Q_{a, z} x_{v}+\sum_{z \in Z} \sum_{v \in V} \delta_{p, z, v} y_{a, z} x_{v} \leq \overline{\sigma_{a, p}} \quad \forall a, \forall p
$$

- For each special area $w \in W$, we need to respect minimum and maximum level of facilities $a \in A$ :

$$
\underline{\sigma_{a, w}} \leq \sum_{z \in w} Q_{a, z}+y_{a, z} \leq \overline{\sigma_{a, w}} \quad \forall w, \forall a
$$

- For each cell $z \in Z$, its number of facilities is limited by the cell surface:

$$
\sum_{a \in A}\left(s_{a} Q_{a, z}+s_{a} y_{a, z}\right) \leq S_{z} \quad \forall z
$$

- For each facility $a \in A$, we need to respect its total available quantity:

$$
\sum_{z \in Z} Q_{a, z}+\sum_{z \in Z} y_{a, z}=\operatorname{tot}_{a} \quad \forall a
$$

- The reallocation cannot exceed the maximum ratio of land mutation. The mutation ratio is computed by dividing the sum of the changes $\left(\sum_{z \in Z} \overline{y_{a, z}}\right.$ ) of the activity $a$ (before and after relocation) in the cells by the total number of possible changes $\left(2 t_{0} t_{a}\right)$. The coefficient 
2 comes by considering increasing and decreasing number of the activity $a$.

$$
\frac{\sum_{z \in Z} \overline{y_{a, z}}}{2 t_{0}} \leq r_{a} \quad \forall a
$$

- As $\overline{y_{a, z}}$ represents an absolute value, it is a non linear expression. Nevertheless it can easily linearized as follows :

$$
\begin{gathered}
\overline{Q_{a, z}}-\left(Q_{a, z}+y_{a, z}\right) \leq \overline{y_{a, z}} \quad \forall z, \forall a \\
-\left(\overline{Q_{a, z}}-\left(Q_{a, z}+y_{a, z}\right)\right) \leq \overline{y_{a, z}} \quad \forall z, \forall a
\end{gathered}
$$

- Variables values are limited arbitrarily by lower and upper bounds:

$$
\underline{\alpha_{a, z}} \leq y_{a, z} \leq \overline{\alpha_{a, z}}, \quad \forall z, \forall a
$$

This optimization problem is a mixed-integer problem with binary and continuous variables. The size of the discrete set $V$ corresponds to the number of binary variables $x_{v} . V$ can be generated by discretizing an interval $\left[\min _{V}, \max _{V}\right]$, formed by the minimal and the maximal possible speeds, with a chosen discretization step. If, for instance, the step is $5 \mathrm{~km} / \mathrm{h}$ and the minimal (resp. maximal) possible speed $30 \mathrm{~km} / \mathrm{h}$ (resp. $130 \mathrm{~km} / \mathrm{h}$ ) then $V$ is composed of 21 speeds. Notice also that the problem is also non-linear, as constraint (3) contains a product of two decision variables. Mixed-integer non-linear problems are usually hard to solve. The classical technique consists in introducing a new variable, replacing each product of two decision variables and thus adding new constraints which link a new variable with the original variables (see Fortet (1959) Fortet (1960)). However, following this process, solving directly the problem with the software Cplex (12.6.0) needs about 15 hours of CPU times because of a long branch-and-cut process. Thus, making difficult the 
exploration of the different scenarios, and necessary the implementation of an alternative resolution method.

\section{Resolution method}

By observing the structure of the problem, it can be seen that there are a limited number of binary variables $x_{v}$. 21 variables if we take a discretization step of $5 \mathrm{~km} / \mathrm{h}$ starting from $30 \mathrm{~km} / \mathrm{h}$ until 130 , much less if we increase (resp.decrease) minimal (resp. maximal) possible speed. Moreover, constraint (2) ensures that only one variable of type $x_{v}$ is selected. Therefore, we can resolve the sequence of linear problems which resulted from fixing successively the variables $x_{v}$, defined by the set $V$ in ascending order. When the respective problem is not feasible, we pass to the next higher speed. The process stops as soon as the solution is feasible and therefore optimal, due to the ascending order of the set $V$. The resolution time is considerably reduced (downing to $1 h$ of CPU time) as obviously the branch and cut is not required.

\section{Case study and numerical results}

\section{Study area}

The study area (fig. 1) is a part of Vaucluse in the south-east of France, with 327000 inhabitants and 107000 jobs. These are mainly located in the major city in the middle of the area, Carpentras (28000 inhabitants) but also in smaller neighboring villages. A smaller area inside the study area represents the reaffectable area (83000 inhabitants and 21000 jobs), where it was considered that the decision-maker is authorized to reallocate activities. This differentiation was necessary to avoid a side effect, because in reality, planning areas are not islands and people can also access activities in the surrounding. Thus, it is necessary to take surroundings into account when computing accessibility and density, even if reallocations of activities are impossible outside the reaffectable area. The study area 
was divided into 6095 square cells (500m x 500m), with 1304 cells in the reaffectable area, approximately corresponding to the municipalities included in a radius of $10 \mathrm{~km}$ around Carpentras. The current mean SIP of the reaffectable area is 51000 and the density is 225 residents per $\mathrm{km} 2$ (but both with a high standard deviation). The average travel speed from cell to cell is $53 \mathrm{~km} / \mathrm{h}$.

Figure 1. Study area and reaffectable area

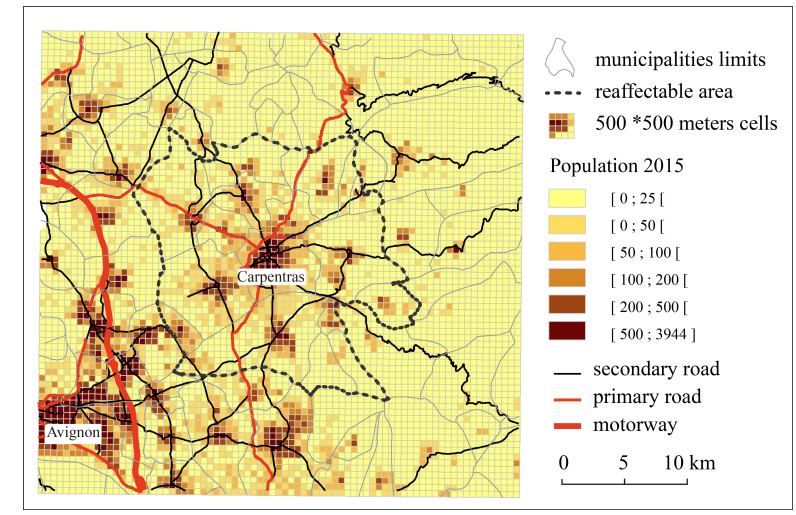

In this paper, rather than give a full case study, some selected results and model output are presented to illustrate the capacities of OPTIDENS as an exploratory tool. For fair comparisons, different parameters were set as equal for the different simulations. Hence, the measurement points are the centers of the cells and the expectations are the same for all of them. The required surface per person and per job is respectively $90.5 \mathrm{~m} 2$ per person and $54.75 \mathrm{~m} 2$ per job, which represents the average values observed in the study area. The compactness is $70 \%$ for all the simulations. It can therefore be deducted that the population per cell cannot exceed 1933 inhabitants $([(500 * 500) * 0.7] / 90.5=1933)$. All the cells in the reaffectable area are constructible, and the is not limit for local density unless mentioned otherwise. Accessibility was computed with a travel time of 15 minutes. 


\section{Accessibility to population and required speed}

First we consider the level of SIP and observe the respective speeds. Logically, the higher the SIP, the higher the required speed, but without this being strictly proportional. For a range of SIP from 30 to 70 thousand, the required speed varies for a mutation ratio of between 20 and $100 \%$ from 45 to $65 \mathrm{~km} / \mathrm{h}$.

Figure 2. Required speed according to the level of SIP

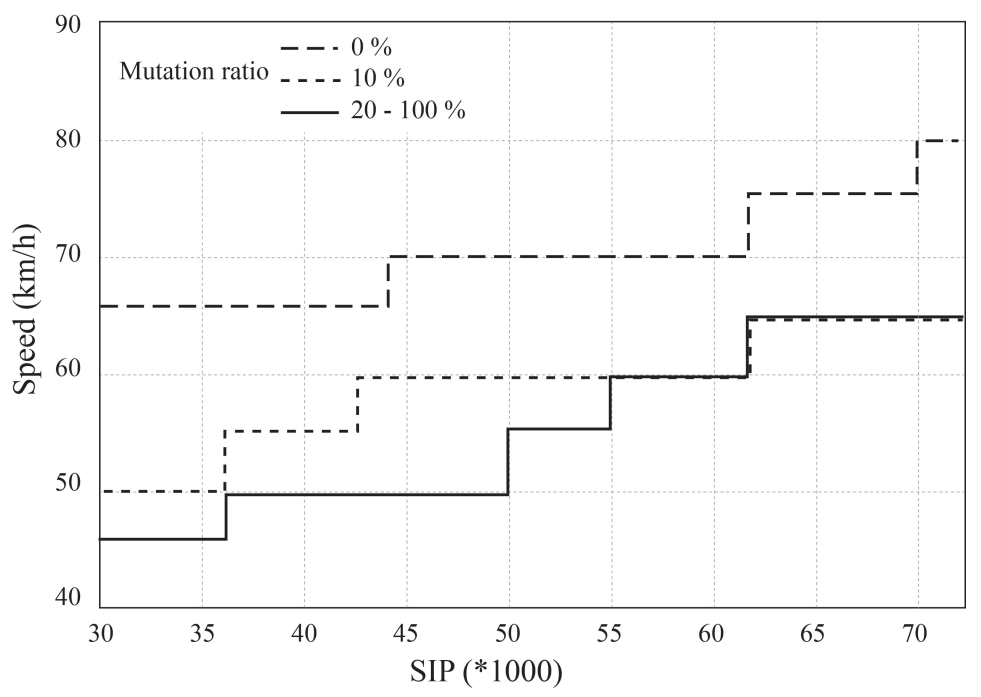

A decrease in the mutation ratio (the $\%$ of activity available for the relocation process) logically induces an increase in the required speed, whose intensity varies depending on the level of SIP considered. In practice, the lower the mutation ratio (corresponding to a weak urban dynamic), the lower the flexibility for the optimization process, which rises to higher required speeds. It can also be noted that the constraints can be satisfied for a mutation ratio of zero, but with speeds ranging from 65 to $80 \mathrm{~km} / \mathrm{h}$. This is the situation experienced in most urban areas for 40 years, when high levels of accessibility have been targeted only 
through an increase in transportation speed rather than by looking for an optimal location of activities. It can also be seen that for SIP above (or around) 61000 , the speed remains the same whatever the mutation ratio when above $20 \%$. In the simulations, thresholds between $10-20 \%$ of mutation ratio very often appear to be strategic to meet the expectations with suitable speeds. This shows that planners obtain a real margin of maneuver to optimize the current city as long as they face a sufficient dynamic.

Spatially, the right of the figure 3 shows that there are major differences in the required speed among the measurement points (It should be remembered that the value returned by the software after the optimization is the speed required for the worst case). For example, for an SIP of 50000 and a mutation ratio of $10 \%$, the speed varies from 28 to $60 \mathrm{~km} / \mathrm{h}$.

Regarding the distribution of the population (figure 3 left), the relocation process tends to favor the cells initially with low populations around them, which rises to a more uniform distribution. Here, the population is relocated in the east of the reaffectable area, because in the west there is the city of Avignon (85000 inhabitants). This is the major city of the study area reachable in 15 minutes from the measurement points of the west, even if it is outside the reaffectable area. This illustrates the importance of taking into account the border effect when computing accessibility.

If the simulations are run with various SIP levels for the measurement points, in general higher speeds are required as there are less achievable reallocations. This possibility of setting different levels of constraints, is very important to ensure practical application of OPTIDENS. because it enables simulations to be run depending on a political project, assuming for example higher levels of accessibility for the city center or around public transport infrastructures. 
Figure 3. Population after relocation and local speed required for a SIP of 50000 and a mutation ratio of $10 \%$

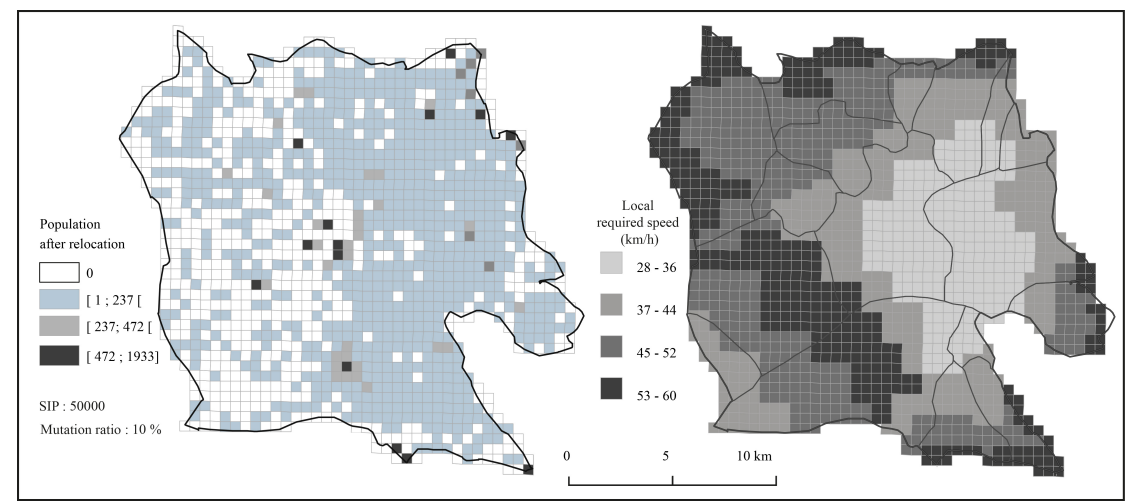

\section{Speed and constructability restrictions}

To estimate the relative importance of the current planning documents, simulations were run where reallocations were possible only in cells which are currently considered as constructible. They represent only $13 \%$ of the surface of the reaffectable area, because there are numerous natural risks in the study area, including floods and forest fires. Hence the case study is not truly representative (generally the percentage of constructible area is higher), but it is interesting from a heuristic perspective to illustrate the relative importance of the legislative constraint. For the same levels of SIP as previously mentioned (from 30 to 70 ), the required speed increases by up to $30 \mathrm{~km} / \mathrm{h}$. More specifically the lower the SIP, the higher the impact of the constructability limitation on speed $(+30 \mathrm{~km} /$ for an SIP of 30 , $+10 \mathrm{~km} / \mathrm{h}$ for an SIP of 60 ). As a high SIP requires already high levels of speed, the relative weight of constructability on speed is lower. Spatially, the population is logically concentrated in the constructible cells.

This simulation shows the huge impact on speed of constructability limitations in areas with high constraints. As the optimal location process is cramped in these cases, speed is the only way to ensure a high level of 
accessibility. This illustrates the ability of OPTIDENS to link planning documents, peoples expectations, and their implications for required transportation speed in an original way.

\section{Speed and local density of population}

Fixing a density level is very strategic in urban planning, and this is often a source of conflict. Briefly, people try to avoid high density levels around their home (one of the main drivers of urban sprawl) while on the contrary urban planners tend to favor density to limit not just land consumption and automobile dependency, but also the length of the utility networks (sewage, water, electricity networks etc.). To illustrate the impact of the density on the required speed, simulations were run for an SIP of 50000 for all the measurement points and for several mutation ratios (see fig. 4).

Figure 4. Required speed depending on the population density level, SIP 50000

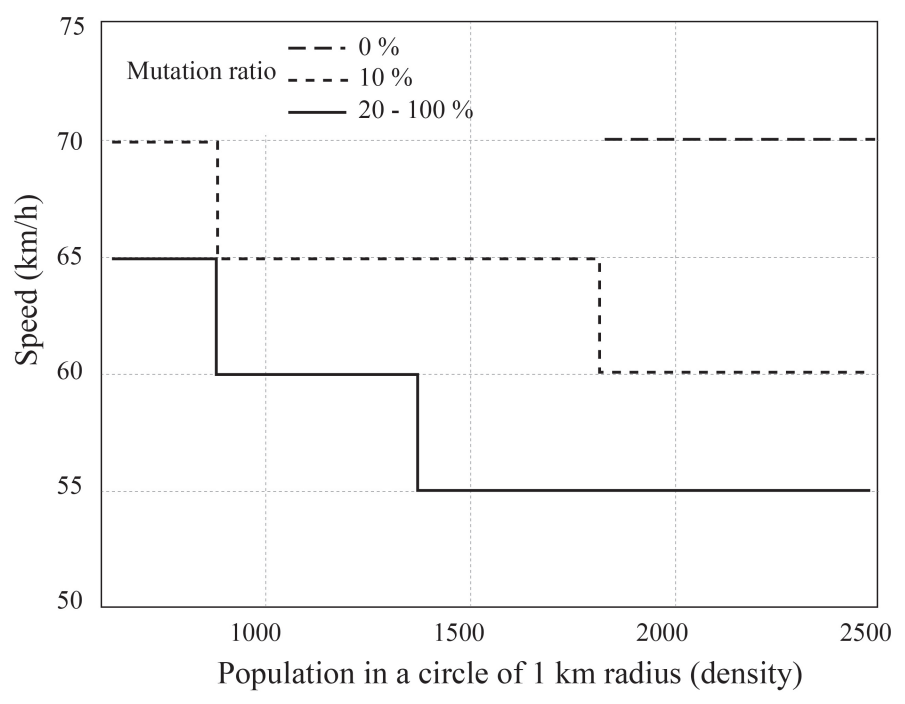

Logically, the lower the population allowed in a circle with a radius of 1 kilometer, the higher the required speed. In this case the population has to be more scattered, in particular in dense areas, to respect the constraint 
of density, which leads to higher speeds to ensure accessibility. Higher mutation ratios enable, as previously shown, a lower speed increase. Hence, OPTIDENS enables an illustration of the extent to which the rejection of density at a local scale impacts urban functioning at a large scale in terms of the speed required to ensure accessibility. This ability to articulate different scales is interesting, because most of the time levels of density are defined at the scale of the plot or of the urban development operation without any lever to estimate their impact on urban functioning as a whole. In a practical use of OPTIDENS, the impact of density will be lowered by the fact that the allowed density will arguably vary for the different measurement points to take into account the current urban structure.

Regarding compactness, it appears that its impact on speed is quite low in the study area. On average, a threshold of compactness under $50 \%$ leads to an increase of $5 \mathrm{~km} / \mathrm{h}$. This very relative impact is explained by the fact that the study area is not intensively built up. It may be very different in denser urban areas.

\section{Accessibility to several activities and required speed}

Until now, simulations have been based only on accessibility to population. However in OPTIDENS it is possible to take into account many types of activities simultaneously (SIP, accessibility to jobs, shops...) as shown in this section, with accessibility to population and to jobs. All the cells are constructible, the compactness is $70 \%$ and there is no density limit.

Adding job accessibility as a supplementary criterion significantly impacts the speed for values higher than 15000 jobs reachable in 15 minutes. On average, it results in an increase of $10 \mathrm{~km} / \mathrm{h}$ (figure 5). This increase is higher for low values of SIP for a given threshold of jobs, because in the case of high SIP the required speed is sufficient to meet 
all the constraints (SIP is a deciding factor). For example, a threshold of 15000 jobs leads to an increase of $10 \mathrm{~km} / \mathrm{h}$ for an SIP of 50000 , but does not cause any change for an SIP of 70000. As explained before, the higher the mutation ratio, the lower the speeds, because the optimization process has a higher degree of freedom .

Figure 5. Required speed depending on the level of jobs accessibility for an SIP of 50000

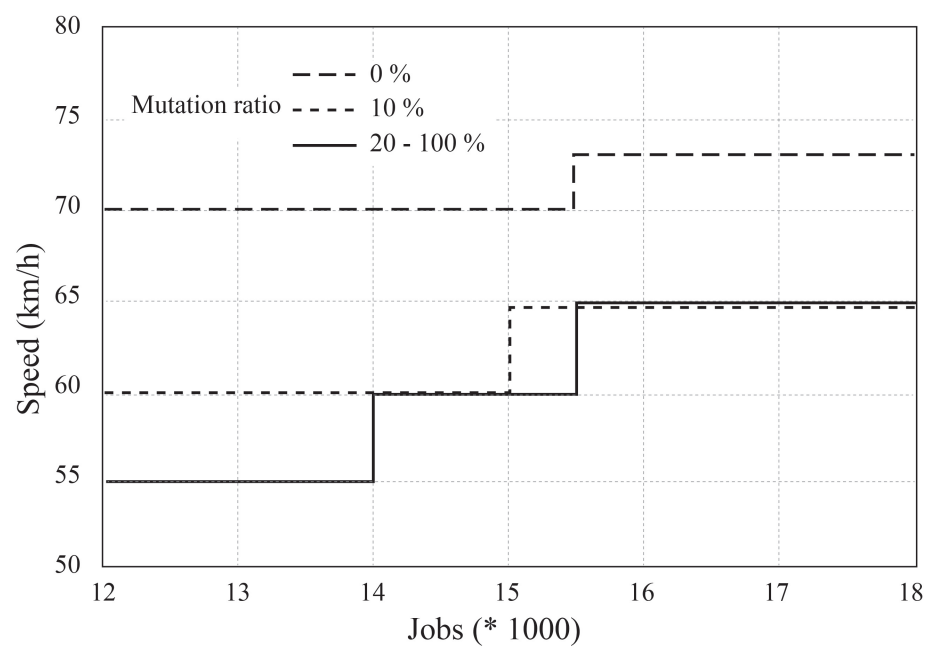

Spatially, as for the population, when the same level of jobs is required for all the measurement points, OPTIDENS scatters the jobs which are currently concentrated in the central urban cluster of Carpentras, to the advantage of areas offering few jobs. While theoretically it is possible to add many types of activity, it should however be noted that this means an increase in calculation duration, and then the difficulty to encompass the relative impact of each factor on the resulting speed.

Finally, simulations were run with rising levels of expectations and constraints to test the limit of the model. Thus with high SIP ( $>$ $55000)$ and accessibility to jobs (>30000), low local density (450 inhabitants $/ \mathrm{km}^{2}$ ), a compactness of $70 \%$ and a limitation of the 
constructability under the current legislation (13\% of the area of the reaffectable area), it appears that it becomes impossible to find a reasonable travel speed to meet all the requirements (the required speed is $120 \mathrm{~km} / \mathrm{h}$ or more). This finding shows that planning in a sustainable perspective may be a question of choice, and that it is not always possible to fully respect all the demands and interests. Certainly optimization can help reach compromises between numerous and contradictory expectations, but sometimes there are no truly suitable solutions. In this case, OPTIDENS may be used as a tool to help planners and stakeholders to find the best compromise, or at least to be aware that sustainability will often be accompanied by choices undesired at a personal level.

\section{Conclusion}

Accessibility results from travel speed but also from activity locations, as planners and transport engineers sometimes tend to forget. Hence, in a sustainable perspective it seems strategic to switch from planning for mobility (which mainly results in an increase in travel speed by car and in its negative external impacts) to planning for accessibility, which leads to simultaneously considering travel conditions and activity locations in order to overcome the automobile dependency issue. To tackle the link between urban forms, travel speeds, and the resulting accessibility, in OPTIDENS the approach consists in exploring under what conditions (in terms of activity relocation), a slow but accessible city is possible. This exploratory model may enable planners to explore further than preconceived forms and functioning of the city and widen the catalog of urban forms beyond the franchised forms (Mangin (2004)). Furthermore, Optidens can be useful as a collaborative tool for participative planning to work on the future of urban forms, as it enables to enhance the 
whys and wherefores of different expectations regarding urban form and accessibility.

The preliminary results emphasize that a decrease in transportation speed can be balanced by suitable relocations to maintain accessibility, but also that even with optimization methods it is sometimes difficult to reconcile contradictory goals (accessibility versus low density and compactness), which should lead to the necessary compromises on the way to sustainability. The study of the relative contribution of the different constraints underlines the importance of the constructability of the area and of the mutation ratio, which condition the relevance of the relocation process. However, in order to deepen and to try to generalize the relative importance of the different criteria, it remains necessary to test OPTIDENS on other case studies, especially in denser areas, where compactness would certainly be more important. We will also exploit the ability of OPTIDENS to optimally locate new activities, to test the model in a perspective of growth. Note that if it was chosen here to present simulations of relocation, rather than location, this is because it seemed important to emphasize the huge reserve to optimize the urban functioning encompassed in changing current urban forms. This finding appears to be very important for low growth or shrinking cities. Finally, use will be made of the second objective function which gives the minimum relative change value for the current speeds on different sections of the road network, so that all the expectations are verified. Maybe, this option, which allows a hierarchy to be kept between the arcs of the road network, is more practical for planners, even if it should be noted than more and more cities are in a trend towards decreasing but also homogenizing the speed of their road networks (Grenoble and Chambery in France, for example).

Beyond these first results, and future simulations, several more fundamental improvements are required to improve the operationality of OPTIDENS : 
- to develop a more integrated and user-friendly tool. For example, it seems suitable to be able to calculate the distance matrices between cells in OPTIDENS, rather than to obtain them with another software.

- to consider contiguities between the land-use types in the process of reallocation. The idea is to limit scattered shapes of built-up areas (related to issues of biodiversity, but also to the cost of utility networks) and, at the same time, to prevent some types of contiguities. For example, the contiguity between built-up and green areas has to be favored contrary to the contiguity between built-up areas and polluting or risk-related activities. Some promising tests have already been done to tackle this complex issue using min node cut method.

- lastly, possible reallocations need to be planned in several time periods. As planning occurs on the long term, the idea is to break down the total reallocation or allocation process into several sequences of decision steps over time and to ensure that each step is as suitable as possible on the way to the final configuration.

\section{References}

Aerts J, Eisinger E and Heuvelink G (2003) Using linear integer programming for multi-site landuse allocation. Geographical Analysis 35: 148-169.

Aldous T (1997) Urban Villages: A Concept for Creating Mixed-use Urban Developments on a Sustainable Scale. 2nd edn. London: Urban Villages Forum.

Aretnze T, Hofman F, Mourik V and Timmermans H (2000) Albatross: multi-agent rule based model of activity pattern decisions. Transportation Research Record 1706: 136-144.

Banister D (2011) The trilogy of distance, speed and time. Journal of transport Geography 19: 950-959.

Batty M (2007) Cities and Complexity. Understanding Cities with Cellular Automata, Agent-Based Models, and Fractals. Cambridge MIT Press.

Batty M (2013) The new science of cities. Cambridge MIT Press. 
Bertolini L, Clercq FL and Kapoen L (2005) Sustainable accessibility: a conceptual framework to integrate transport and land use plan-making. two test-applications in the netherlands and a reflection on the way forward. Transport Policy 12: 207-220.

Breheny M (1992) The contradictions of the compact city: A review. In: Breheny MJ. et al. (eds) Sustainable Development and Urban Form. London: Pion Limited. pp. 138-159.

Burton E (2000) The compact city: just or just compact? a preliminary analysis. Urban Studies 37(11): 1969-2001.

Curtis C (2008) Planning for sustainable accessibility: The implementation challenge. Transport Policy 15: 104-112.

Dupuy G (1999) La dépendance automobile. Economica.

Farber S and Li X (2013) Urban sprawl and social interaction potential: an empirical analysis of large metropolitan regions in the united states. Journal of Transport Geography 31: 267-277.

Farber S, Neutens T, Carrasco J and Rojas C (2014) Social interaction potential and the spatial distribution of face-to-face social interactions. Environment and Planning B: Planning and Design 41(6): 960-976.

Fortet R (1959) L'algèbre de boole et ses applications en recherche opérationnelle. Cahier du Centre d'Etudes de Recherche Opérationnelle 1: 5-36.

Fortet R (1960) Application de l'algèbre de boole en recherche opérationnelle. Revue Française de Recherche Opérationnelle 4: 17-26.

Genre-Grandpierre C (2007) Des réseaux lents contre la dépendance automobile ? concept et implications en milieu urbain. L'Espace Géographique 1: 27-39.

Glaeser E (2011) Triumph of the City: How Our Best Invention Makes Us Richer, Smarter, Greener, Healthier, and Happier. New York: Penguin Press.

Handy S and Niemeier D (1997) Measuring accessibility: an exploration of issues and alternatives. Discrete Applied Mathematics 29(7): 1175-1194.

Janssen R, van Herwijnen MM, TJ TS and Aerts J (2008) Measuring accessibility: an exploration of issues and alternatives. Environment and Planning B: Planning and Design 35(4): 740-756.

Levinson D and Kumar A (1994) The rational locator: why travel times have remained stable? Environment and Planning B: Planning and Design 60: 319-332.

Mangin D (2004) Infrastructures et formes de la ville contemporaine. La ville franchisée. Paris : La documentation française.

Neuman M (2005) The compact city fallacy. Journal of Planning Education and Research 25: 11-26. 
Newman P and Kenworthy J (1989) Cities and Automobile Dependence. An International Sourcebook. Brookfield: Gower Publishing.

Nikkami D, Shabani M and Ahmadi H (2009) Land use scenarios and optimization in a watershed. Journal of Applied Sciences 9: 287-295.

Piron O (2003) Renouvellement urbain. Analyse systémique. Paris: La documentation française.

Porta J, Parapar JJ, Doallo R, Rivera F, Santé I and Crecente R (2013) High performance genetic algorithm for land use planning. Computer, Environment and Urban Systems 37: 45-58.

Prudhomme R and Lee C (1999) Size, sprawl, speed and the efficiency of cities. Urban Studies 36(11): 1849-1858.

Tan S, Zhang L, Zhou M, Li Y, Wang S and Kuang B (2017) A hybrid mathematical model for urban land-use planning in association with environmentalecological consideration under uncertainty. Environment and Planning B: Urban Analytics and City Science 44(1): 54-79.

Urry J (2002) Mobility and proximity. Sociology 36(2): 255-274.

Urry J (2008) Governance, flows, and the end of the car system ? Global Environmental Change 18: 343-349.

Waddell P (2001) Urbansim: Modelling urban development for land use, transportation and environment planning. Journal of the American Planning Association 68(3): 297-314.

Wegener W and Fürst F (1999) Land use transport interaction: state of the art, deliverable 2a of the project transland (integration of transport and land use planning). In: 4th RTD Framwork Programme of The European Commission.

White R, Engelen G and Uljee I (2015) Modeling Cities and Regions as Complex Systems: From Theory to Planning Applications. MIT Press.

Wiel M (2002) Ville et automobile. Paris: Descartes et Cie.

Yamu C and Frankhauser P (2015) Spatial accessibility to amenities, natural areas and urban green spaces: using a multiscale, multifractal simulation model for managing urban sprawl. Environment and Planning B: Planning and Design 42: 1054-1078.

Zahavi Y and Talvitie A (1980) Regularities in travel time and money expenditure. Transportation Research Record 750: 13-19. 